\title{
Synthesis and Characterization of Polymerizable Phosphorescent Platinum(II) Complexes for Solution-Processible Organic Light-Emitting Diodes
}

\author{
Jian-Yang Cho,Benoit Domercq, Stephen Barlow, Kyrill Yu. Suponitsky, Jennifer Li, \\ Tatiana V. Timofeeva, Simon C. Jones, Lauren E. Hayden, Alpay Kimyonok, \\ Clinton R. South, Marcus Weck, Bernard Kippelen, Seth R. Marder \\ Center for Organic Photonics and Electronic and \\ School of Chemistry and Biochemistry, Georgia Institute of Technology, Atlanta, GA 30332-0400 \\ School of Electrical and Computer Engineering, Georgia Institute of Technology, Atlanta, GA 30332-0250 \\ Department of Natural Sciences, New Mexico Highlands University, Las Vegas, NM 87701 \\ Institute of Organoelement Compounds, Moscow, Russia
}

\section{Supporting Information}

Figure S1. ${ }^{1} \mathrm{H}$ NMR spectrum of 4.

Figure S2. ${ }^{13} \mathrm{C}\left\{{ }^{1} \mathrm{H}\right\}$ NMR spectrum of 4 (\#: keto form; *: enol form).

Figure S3. Distortionless Enhancement by Polarization Transfer experiment of 4.

Figure S4. HETeronuclear chemical shift CORrelation experiment of 4.

Figure S5. Summary of the resonance assignments of keto and enol forms of 4 in NMR.

Figure S6. ${ }^{1} \mathrm{H}$ NMR spectrum of poly-10 in $\mathrm{CDCl}_{3}$.

Figure S7. ${ }^{1} \mathrm{H}$ NMR spectrum of poly-22-co-10 in $\mathrm{CDCl}_{3}$.

Figure S8. ${ }^{1} \mathrm{H}$ NMR spectrum of poly-22-co-11 in $\mathrm{CDCl}_{3}$.

Figure S9. ${ }^{1} \mathrm{H}$ NMR spectrum of poly-22-co-12 in $\mathrm{CDCl}_{3}$.

Figure S10. The disordered orientations of hydrocarbon substituents over two positions with equal occupancies are shown. 


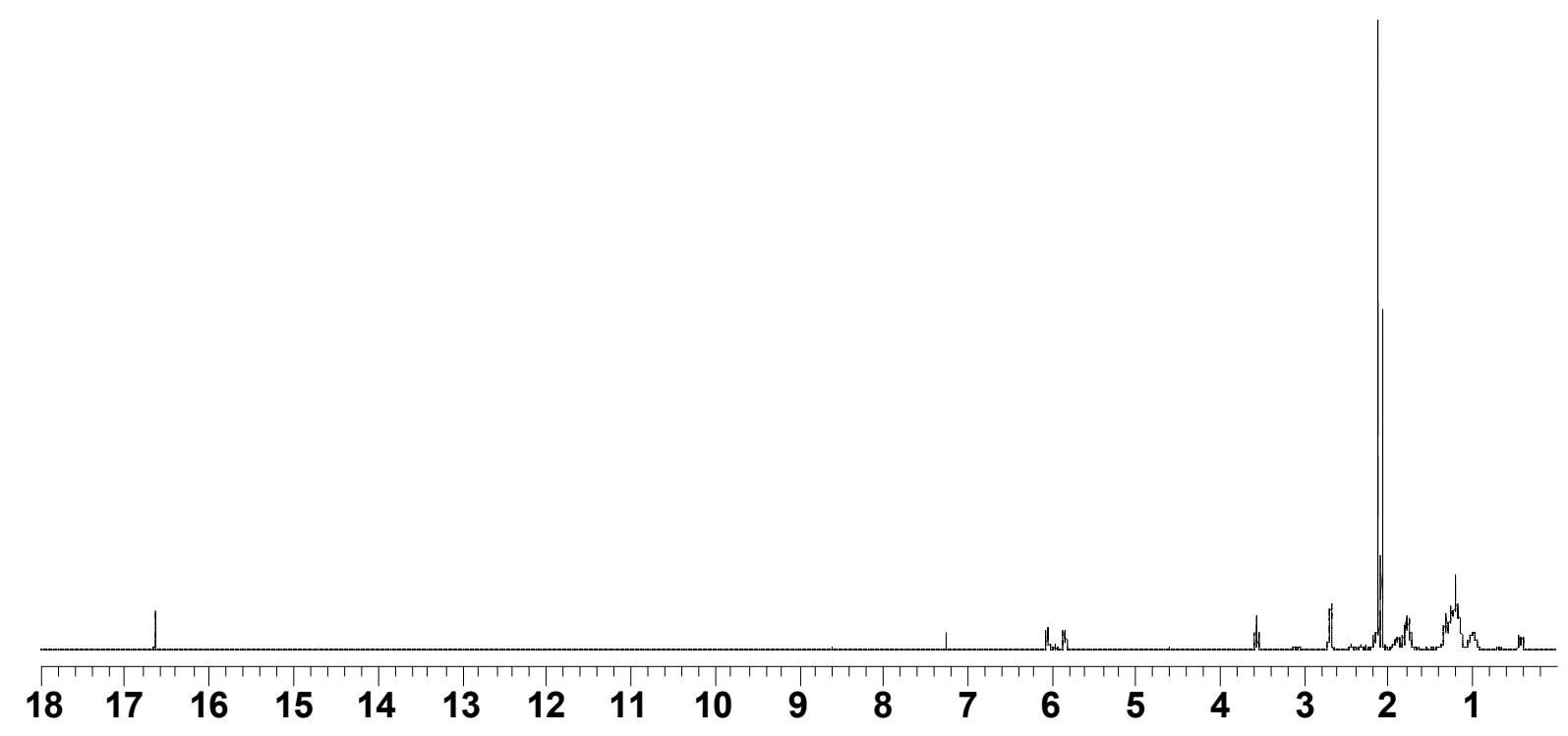

Figure S1. ${ }^{1} \mathrm{H}$ NMR spectrum of 4.

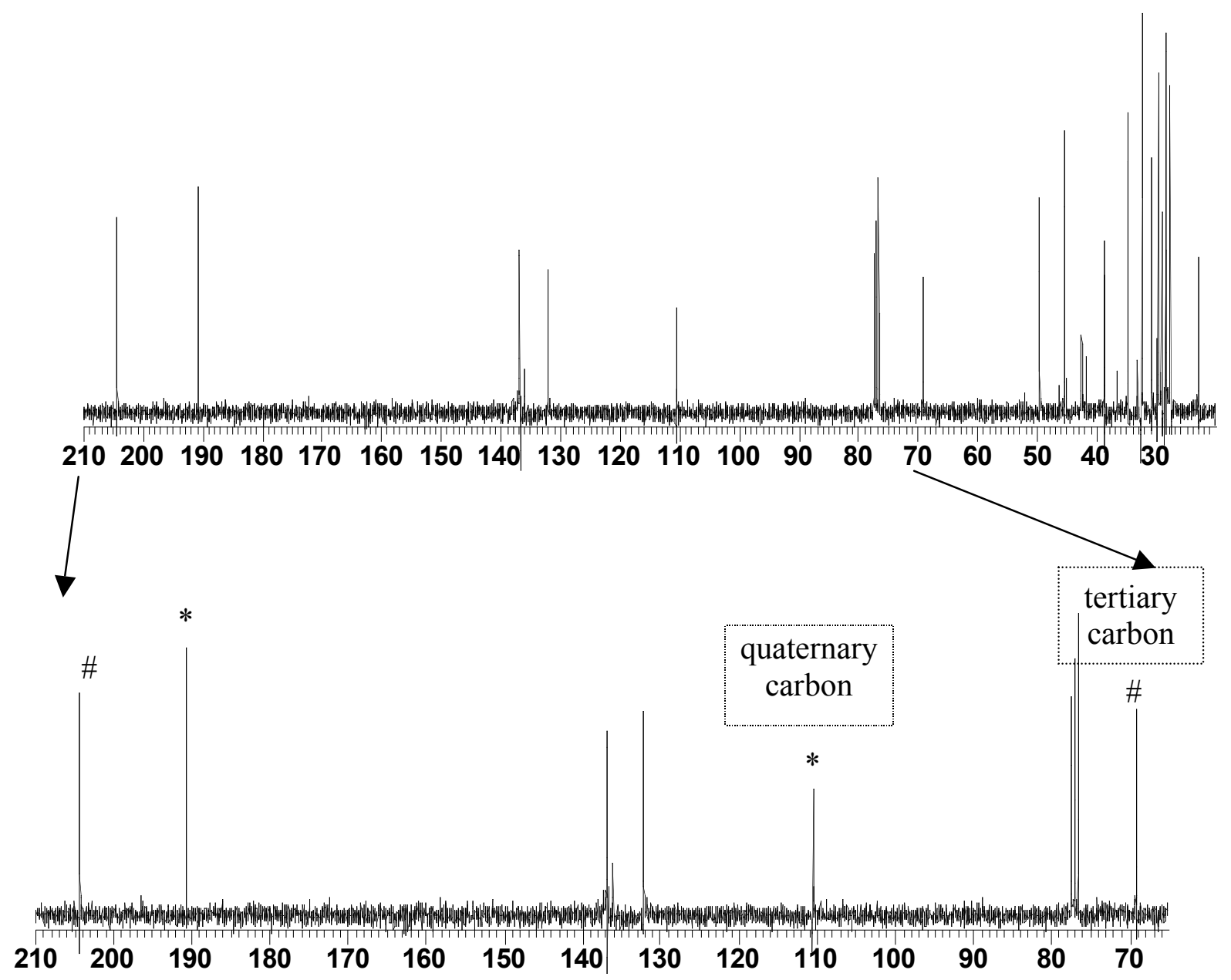

Figure S2. ${ }^{13} \mathrm{C}\left\{{ }^{1} \mathrm{H}\right\}$ NMR spectrum of 4 (\#: keto form; *: enol form). 


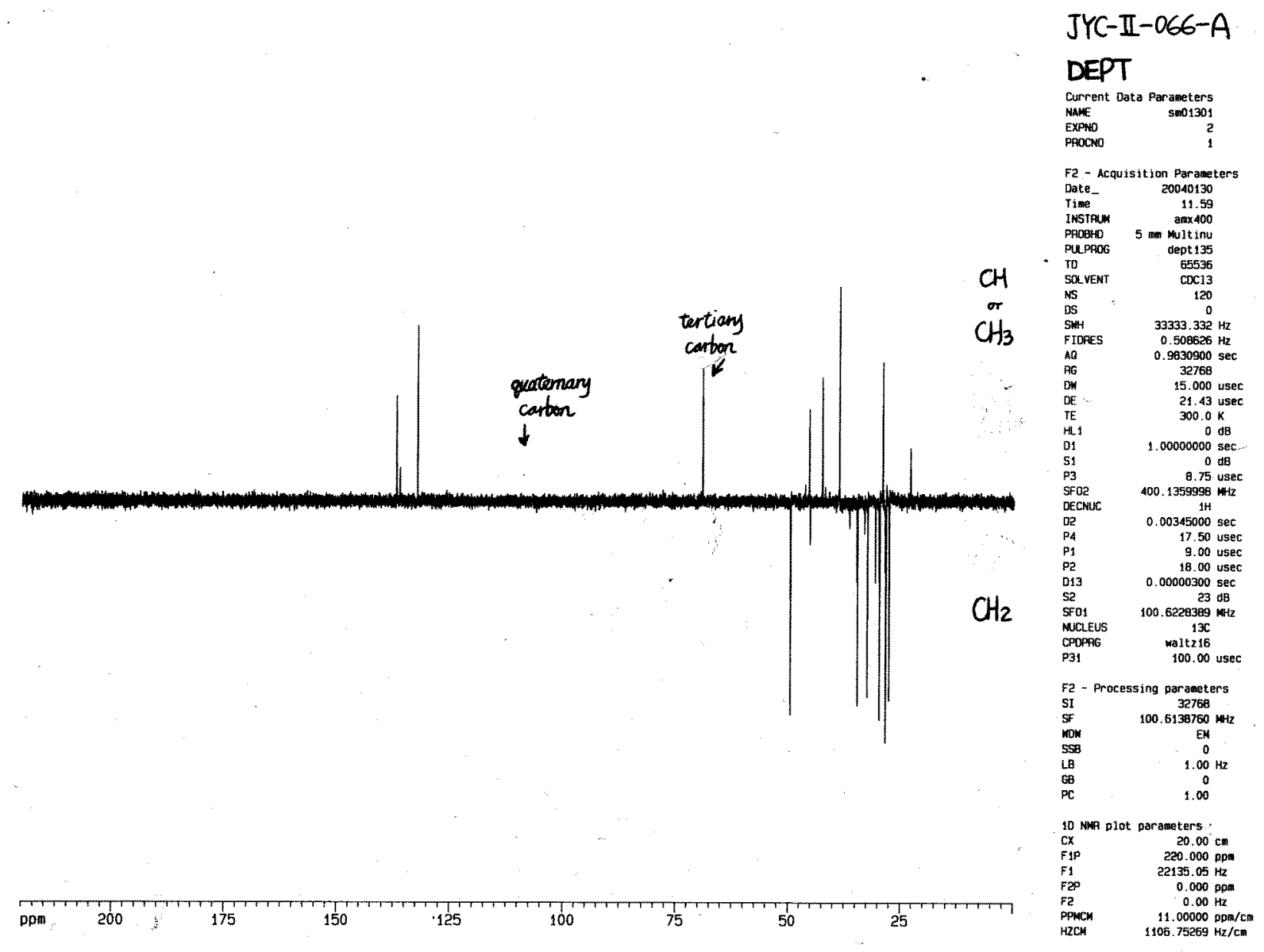

Figure S3. Distortionless Enhancement by Polarization Transfer experiment of 4. 


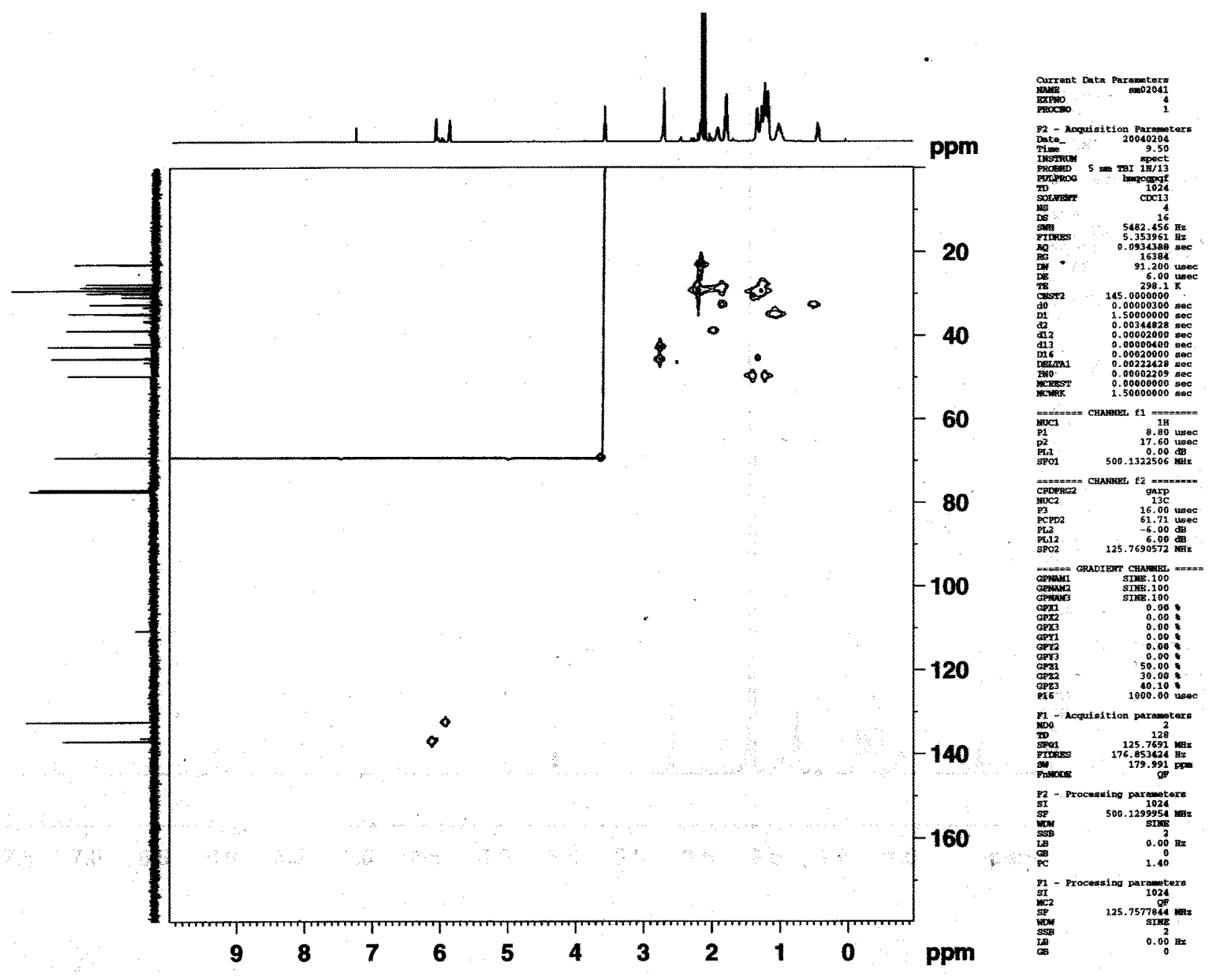

Figure S4. HETeronuclear chemical shift CORrelation experiment of 4.

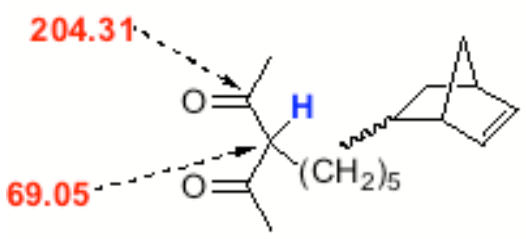

Keto form: ( ${ }^{1} \mathrm{H}$ NMR)

6.05-6.08 $(\mathrm{m}, 1 \mathrm{H}), 5.84-5.87(\mathrm{~m}, 1 \mathrm{H})$,

$3.56(\mathrm{t}, \mathrm{J}=7.4 \mathrm{~Hz}, 1 \mathrm{H}), 2.70(\mathrm{br}, 2 \mathrm{H})$,

$2.13(\mathrm{~s}, 6 \mathrm{H}), 0.40-2.00(\mathrm{~m}, 15 \mathrm{H})$.

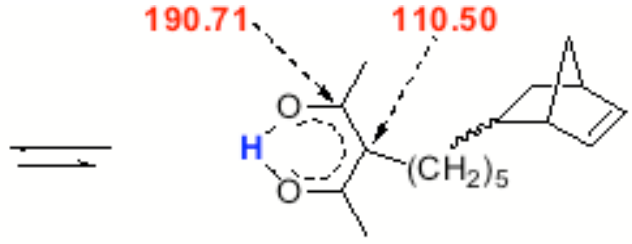

Enol form: $\left({ }^{1} \mathrm{H}\right.$ NMR)

$16.63(\mathrm{~s}, 1 \mathrm{H}), 6.05-6.08(\mathrm{~m}, 1 \mathrm{H})$,

5.84-5.87 (m, 1H), $2.70(\mathrm{br}, 2 \mathrm{H})$,

$2.09(\mathrm{~s}, 6 \mathrm{H}), 0.40-2.00(\mathrm{~m}, 15 \mathrm{H})$.

Figure S5. Summary of the resonance assignments of keto and enol forms of $\mathbf{4}$ in NMR. 


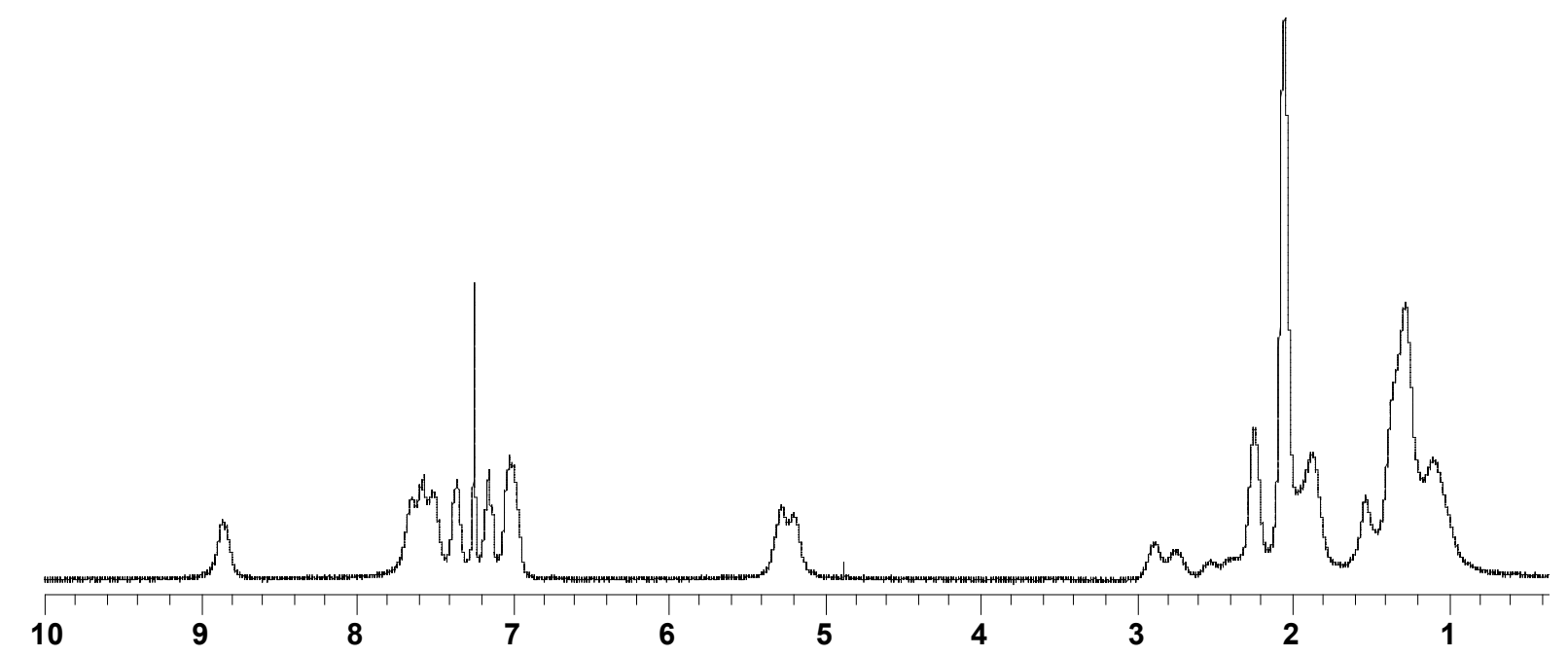

Figure S6. ${ }^{1} \mathrm{H}$ NMR spectrum of poly-10 in $\mathrm{CDCl}_{3}$.

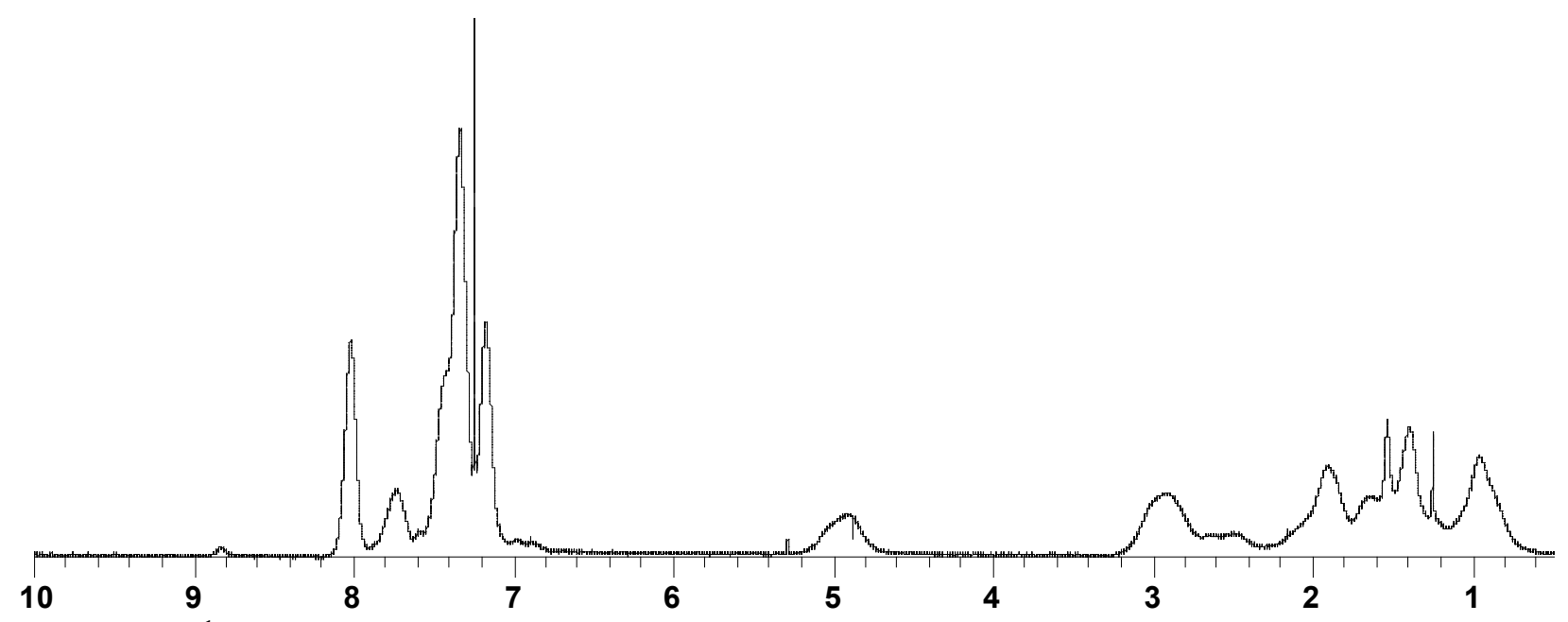

Figure S7. ${ }^{1} \mathrm{H}$ NMR spectrum of poly-22-co-10 in $\mathrm{CDCl}_{3}$. 


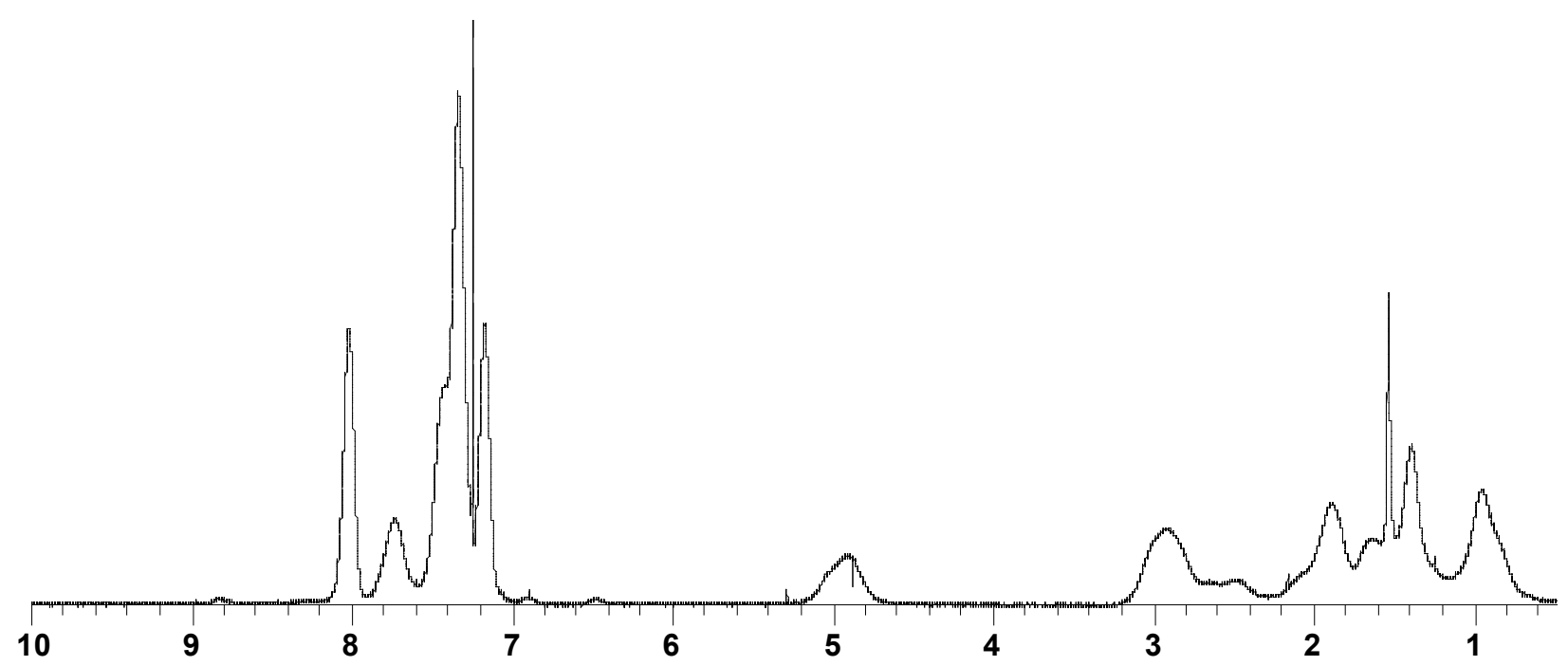

Figure S8. ${ }^{1} \mathrm{H}$ NMR spectrum of poly-22-co-11 in $\mathrm{CDCl}_{3}$.

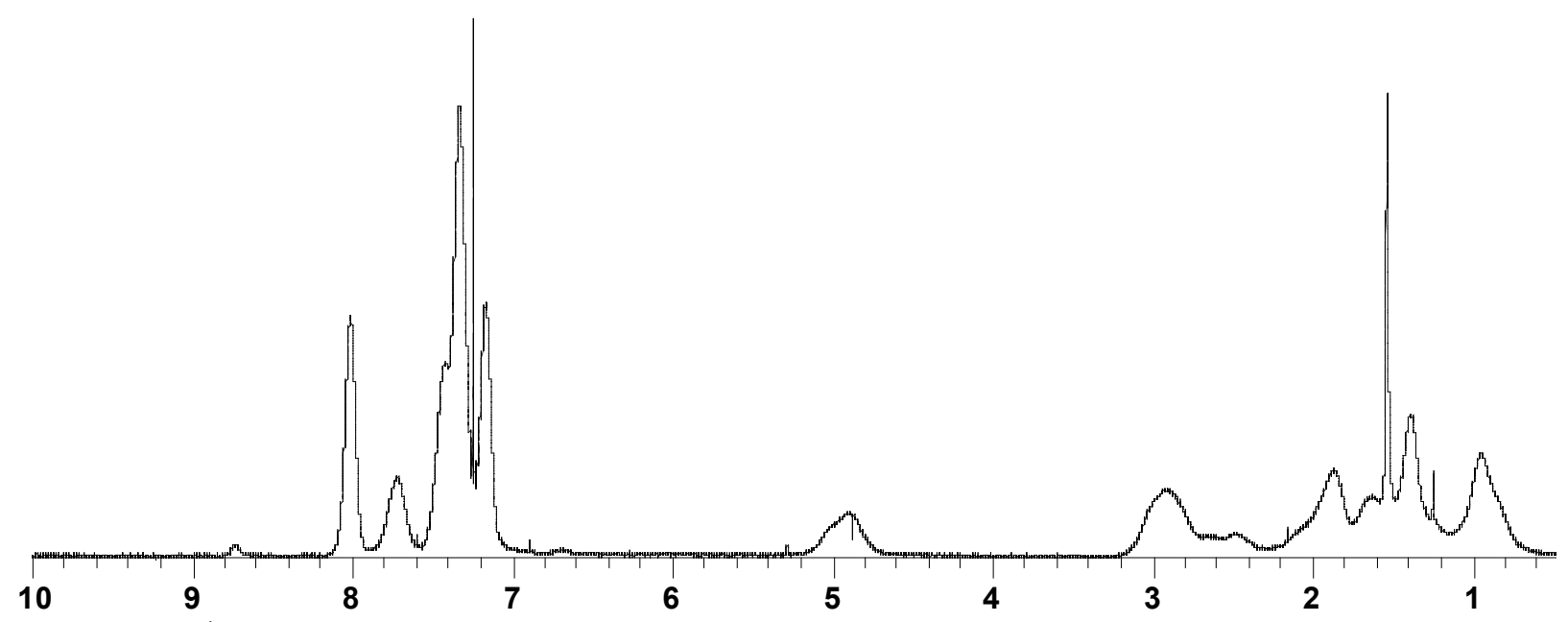

Figure S9. ${ }^{1} \mathrm{H}$ NMR spectrum of poly-22-co-12 in $\mathrm{CDCl}_{3}$. 


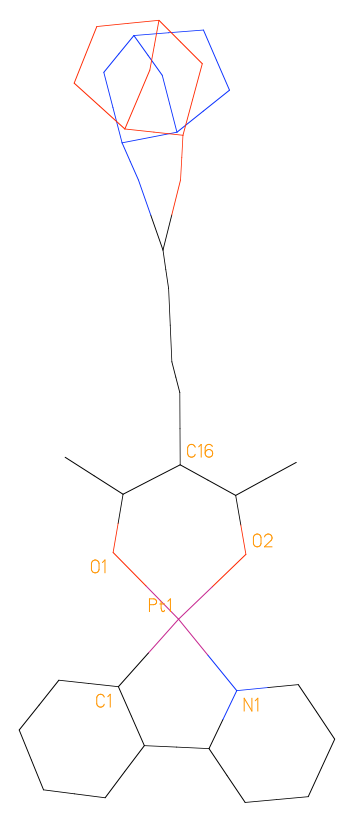

10

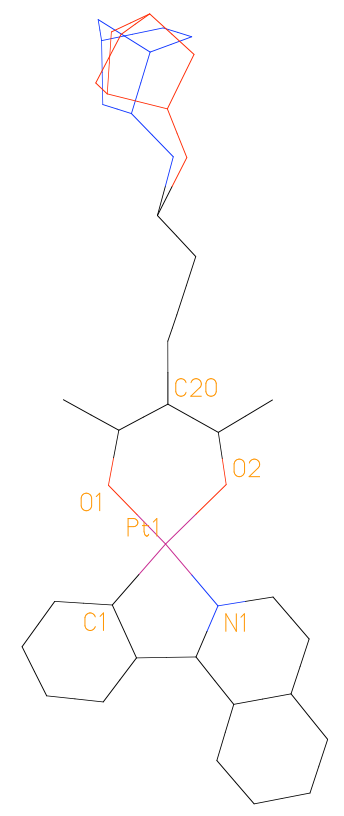

12

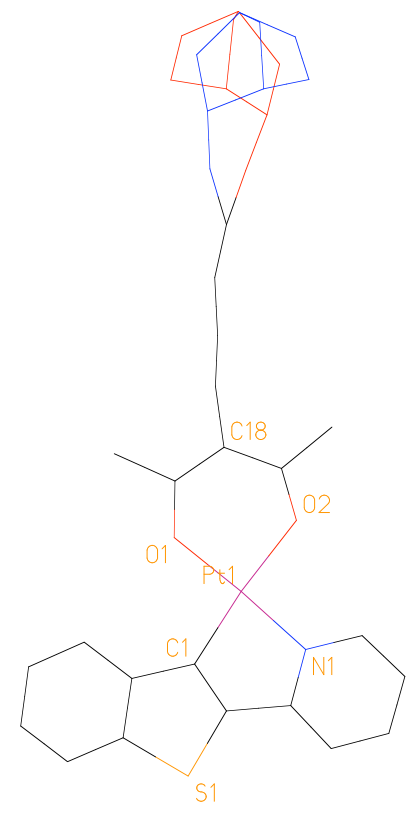

13

Figure S10. The disordered orientations of hydrocarbon substituents over two positions with equal occupancies are shown. 